\title{
Splanchnic Vein Thrombosis
}

National Cancer Institute

\section{Source}

National Cancer Institute. Splanchnic Vein Thrombosis. NCI Thesaurus. Code C150134.

Thrombosis within the hepatic portal system. 